\title{
Basic Principles of Betavoltaic Elements and Prospects of their Development
}

\author{
A.A. Davydov, Ye.N. Fyodorov, D.S. Kiselev, A.V. Popkova \\ Federal State Unitarian Enterprise "Scientific Industrial Association Scientific Research Institute "LUCH", \\ 24, Zheleznodorozhnaya st., 142100 Podolsk, Moscow Region, Russia
}

(Received 04 May 2016; published online 03 October 2016)

\begin{abstract}
The basic technical principles and means of increase in betavoltaitic elements effectiveness have been analyzed by comparing with their closest analogue - photoelectric semiconductor converters. The geometric parameters of radiation sources for these elements and their capacities have been estimated. It is shown the radiation source ${ }^{63} \mathrm{Ni}$ foil thickness should not exceed a few micrometers, and maximum energy conversion efficiency can achieve $\sim 16 \%$.
\end{abstract}

Keywords: Direct conversion of nuclear energy into electrical energy, Radionuclide, Nickel-63, Schottky barrier, Rectifying heterostructure.

DOI: 10.21272/jnep.8(3).03049

PACS numbers: 73.30. $+\mathrm{y}, 73.40 .-\mathrm{c}$

\section{INTRODUCTION}

At present, due to microsystems development a need in autonomic power source is intensified that could provide perennial independent power supply of microelectronic technology [1]. In particular, such equipment is required for the following urgent tasks solutions:

a. Distributed multifunctional monitoring of technical condition control systems, safety and protection of various objects based on microsensors;

b. Maintenance of stand-by in the systems that provide putting on main apparatus when entering commands or upon achieving the set point of controlled external parameter.

Developments of semiconductor devices carrying out direct energy conversion of charged particle radiation called nuclear batteries (NB) of the second type [2] began in the early fifties of the last century. However, demand for such devices and their efficiency was too small at that time. Today these devices are often called betavoltaitic elements, and prospects of their efficiency improvement are associated with application of modern semiconductor materials and technologies.

\section{THE FUNDAMENTAL PRINCIPLES OF SEM- ICONDUCTOR NUCLEAR BATTERIES}

The operational principle of such NB is based on generation of non-equilibrium charge carriers (electronhole pairs) in semiconductors under the charged particles influence emitted by radionuclides and their separation by rectifying contact electric field conducting current in one direction only. In this case thermodynamic contact equilibrium is broken, and an electromotive force appears in the external electric circuit. This principle is similar to the semiconductor photovoltaic cells (solar cells) principle, which use light radiation for formation of electron-hole pairs.

A different nature of the radiation causing generation of non-equilibrium carriers in the semiconductor results in different ways of this general principle implementation for solar cells and NB. Generation of nonequilibrium electron-hole pair requires the energy exceeding a band gap of a semiconductor (up to several electron volts). The energy of light quanta is $\sim 1.6$ -
$3.2 \mathrm{eV}$. These rays don't create defects in the semiconductor crystal lattice. These defects are centers of recombination of non-equilibrium charge carriers, and their formation leads to degradation of solar cells characteristics. Transparent coatings with the required thickness are used to protect spacecraft solar cells from such degradation caused by cosmic radiation exposure. At the same time the charged particles energy emitted by radioactive isotopes is thousands times as much as photon energy. Therefore every such particle generates a lot of electron-hole pairs in the semiconductor material. In this case the wide-semiconductors can be used, however a risk of radiation-induced defects increases, which should be reduced by mutual coordination of the radiation source parameters and semiconductor energy converters.

\section{PROSPECTIVE RADIONUCLIDES FOR NUCLEAR BATTERIES}

The radionuclide selection determines NB energy characteristics. These characteristics are changed with time due to reduction in the radiation intensity as radioactive decay and due to deterioration of the semiconductor materials properties when accumulating radiation defects. Formation of such defects associated with atoms displacement in the crystal lattice interstitials depends on the atoms mass ratio and particles bombarding the lattice. The energy of hundreds $\mathrm{keV}$ is required for the mentioned defects formation by $\beta$-particles energy [3], but several dozens of $\mathrm{eV}$ is enough at influence of $\alpha$ particles which are 7294 times as much. Therefore $\beta$ active radionuclides are preferable in NB for microelectronics.

These nuclides are to meet the following requirements:

a) A half-life shall be substantially higher than the specified battery life;

b) Penetrating gamma and X-ray radiation accompanying the radionuclide decay shall be minimal;

c) $\beta$-particles emitted shall not cause formation of a significant amount of radiation-induced defects in used semiconductor materials;

d) Radionuclide shall be produced on an industrial 
scale in sufficient quantities at a relatively low cost.

Examples of some isotopes largely meeting the above requirements are given in Table 1.

Table 1 - Characteristics of radionuclides

\begin{tabular}{|l|l|c|c|l|}
\hline $\begin{array}{l}\text { Radio- } \\
\text { nuclide }\end{array}$ & $\begin{array}{l}\text { Half- } \\
\text { life, } \\
\text { years }\end{array}$ & $\begin{array}{l}\text { Emitted } \\
\text { particles }\end{array}$ & $\begin{array}{l}\text { Max/average } \\
\text { particle } \\
\text { energy, keV }\end{array}$ & $\begin{array}{l}\text { Specific } \\
\text { energy } \\
\text { consump- } \\
\text { tion, Wt/g }\end{array}$ \\
\hline Tritium & 12.36 & $\beta$ & $18.6 / 6.0$ & 0.329 \\
\hline Nikel-63 & 100 & $\beta$ & $65.9 / 18.0$ & $5.7 \cdot 10^{-3}$ \\
\hline
\end{tabular}

\section{GEOMETRY AND POWER SOURCE}

Emitted particles flow power is determined by surface activity of the radioactive material. However this quantity is limited by radiation absorption in the radioactive material. The radiation absorption is characterized by a path length of $R$ emitted particles. Obviously that it is not expedient to use the radioactive material with the thickness more than $2 \cdot R$ because the radiation from the inner layers will not reach the surface. Consequently, the maximum surface activity does not exceed the value:

$$
A_{s}^{\max }=\frac{\ln (2)}{T_{1 / 2}} N_{A} \frac{\rho \cdot R}{A} K
$$

where: $N_{A}$ - Avogadro's number; $\rho$ and $A$ - the density and atomic mass of a substance containing a radionuclide; $K$ - relative radionuclide content in this substance. At estimation of $\beta$-radiation absorption the formula for the full length of high-energy electrons run obtained by Kanayo and Okayama [4] is often used:

$$
R=\frac{0,0276 \cdot A \cdot(1000 \cdot E)^{5 / 3}}{\rho \cdot Z^{8 / 9}}
$$

where: $E$ - particles energy (keV); $Z$ - atomic number of substance absorbing radiation, and $\rho$ and $R$ values are given in microns and $\mathrm{g} / \mathrm{cm}^{3}$ respectively.

As an example, Fig. 1 shows dependence of the maximum depth of electrons penetration into nickel with the energies in a range of $10-70 \mathrm{keV}$ obtained in accordance with formula (3). The same Figure shows a similar relationship for diamond.

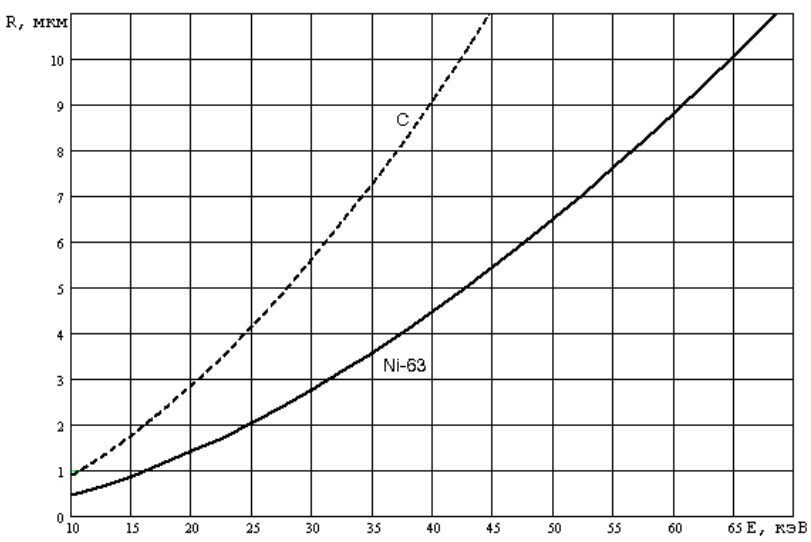

Fig. 1 - Dependences of maximum electrons penetration depth in the nickel-63 and diamond on $\beta$-particle energy
The figure shows that increase in the $\beta$-radioactive material thickness of ${ }^{63} \mathrm{Ni}$ foil more than 20 microns is pointless, a path length and the optimum thickness is $\sim 2 \mathrm{~mm}$ (in accordance with a double path length of the emitted $\beta$-particles). In this case the surface activity of the $\beta$-radioactive material in accordance with the formula (1) will not exceed $\sim 2 \cdot 10^{3} \mathrm{MBq} / \mathrm{cm}^{2}$.

\section{SEMICONDUCTOR CONVERTERS FOR NU- CLEAR BATTERIES AND EFFICIENCY VAL- UATION OF BETAVOLTAITIC ELEMENTS}

$p$ - $n$ transitions in single crystal semiconductors are mainly used as rectifying contacts in solar cells. The contacts based on semiconductors with an amorphous or polycrystalline structure are less sensitive to radiation defects, and that raises interest to their application in NB. It is more expedient to apply the Schottky barrier or rectifying heterostructure in betavoltaitic elements due to $\beta$-particles small penetration depth in semiconductors (see Fig. 1). Fig. 2 shows a diagram of the electron energy of betavoltaitic element with Schottky barrier formed by a $n$-type semiconductor and metal with a high work function. Small particle penetration depth reduces an electric field area rectifying contact and charge carrier diffusion length. It offers prospects of greater application of high-elementary semiconductors and semiconductor compounds characterized by small values of the lifetime and charge carriers mobility than solar cells. Some examples of these materials are given in Table 2.

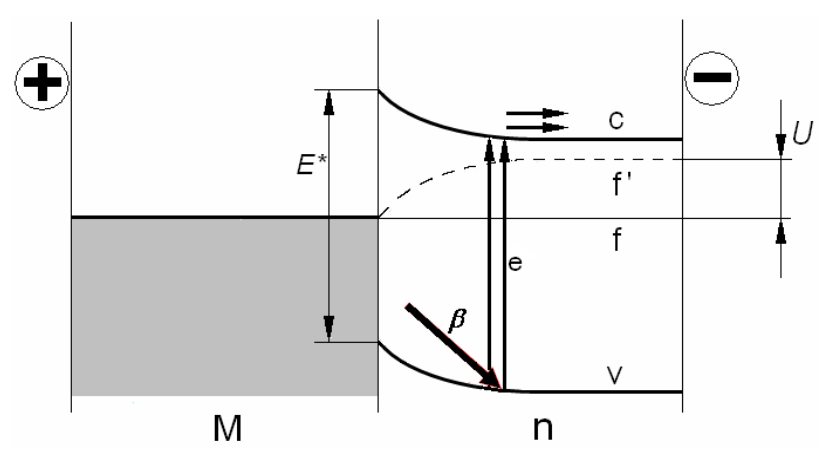

Fig. 2 - Diagram of electron energy in NB with the Schottky barrier: $\mathrm{n}-n$-type semiconductor; $\mathrm{M}-$ metal; $\mathrm{c}-$ conduction band; $\mathrm{v}$ - valence band; $\mathrm{f}, \mathrm{f}^{\prime}-$ equilibrium and non-equilibrium Fermi levels; $\mathrm{E}^{*}$ - band gap; $\beta$ - $\beta$-particles absorption; $\mathrm{e}-$ formation of none-quilibrium charge carriers; $\mathrm{U}$ - output voltage

Maximum efficiency of betavoltaitic element can be estimated by the formula [5]:

$$
\eta=\frac{I_{k 3} \cdot U_{x x}}{P_{\beta}},
$$

where: $I_{s c}$ - short-circuit current; $U_{x x}$ - open circuit voltage; $P_{\beta}$ - power emitting isotopes. The short circuit current is determined by intensity of the electron-hole pairs formation, and it is proportional to the $\beta$-particles flux density. Open circuit voltage can be determined from the Shockley equation, and the radiated power is proportional to the $\beta$-particles energy and their flow.

Substitution of the corresponding expressions in the formula (3) allows us to get an upper bound of betavoltaitic element effectiveness with the Schottky barrier: 
Table 2 - Advanced semiconductor materials

\begin{tabular}{|c|c|c|c|c|c|}
\hline Semiconductor type & \multicolumn{2}{|c|}{ Simple semiconductors } & \multicolumn{3}{c|}{ Semiconductor compounds } \\
\cline { 3 - 6 } & & $\mathrm{A}$ & $\mathrm{A}^{\mathrm{III}} \mathrm{B}^{\mathrm{V}}$ & Chalgenides & Oxides \\
\hline Semiconductor & $\mathrm{Si}$ & Diamond & $\mathrm{GaAs}$ & $\mathrm{CdS}$ & $\mathrm{TiO}_{2}$ \\
\hline Band gap, eV & 1.12 & 5.6 & 1.43 & 2.4 & 3.05 \\
\hline
\end{tabular}

$$
\eta=\frac{k T}{e E^{*}} \ln \left[1+\frac{E}{E^{*}} \cdot \frac{e A_{s}^{\max }}{A_{R} T^{2}} \cdot \exp \left(\frac{e V_{k}}{k T}\right)\right],
$$

where: $T$ - rectifying contact temperature; $E^{*}-$ semiconductor band gap width; $E$ - average $\beta$-particles energy; $V_{k}$ - potential barrier height; $e$ - electron charge; $k$ and $A_{R}-$ Boltzmann and Richardson constants.

Using in equation (4) the material parameters corresponding to the data shown in Tables 1-2 and in Fig. 1, the energy conversion efficiency can be obtained at $\sim 16 \%$.

\section{CONCLUSIONS}

The basic technical principles and ways of increase in

\section{REFERENCES}

1. Ju.S. Nagornov, Actual aspects employments betavoltaitic effect (Ulyanovsk: 2012).

2. W. Corliss, J. Harvey, Sources of energy for radioactive isotopes (Moscow: Mir: 1967).

3. A.M. Vasiliev, A.P. Landsman, Semiconductor photovoltaics (Moscow: The Soviet radio: 1971) betavoltaitic elements effectiveness have been analyzed by comparing with their closest analogue - photoelectric semiconductor converters.

Commutated estimates of the geometric parameters of $\beta$-radioactive material and their capacities have been made. It is shown that the thickness of ${ }^{63} \mathrm{Ni} \beta$-radioactive material shall not exceed a few micrometers, and the maximum energy conversion efficiency can be up to fifteen percent.

\section{ACKNOWLEDGMENT}

This research was supported by Ministry of Education and Science of the Russian Federation, Agreement 14.625.21.0031 dated August 19, 2015, Reference number RFMEFI62515X0102.

4. K. Kanaya, S. Okayama, J. Phys. D.: J. Appl. Phys. 5, 43 (1972).

5. S.Yu. Yurchuk, S.A. Legotin, V.N. Murashev, J. NanoElectron. Phys. 7 No 3, 03014 (2015). 